\title{
The faculty development model of the University of Milan- Bicocca: towards an integration of general and disciplinary didactics
}

\section{Franco Passalacqua, Elisabetta Nigris}

Department of Human Sciences for Education "Riccardo Massa", University of MilanBicocca, Italy.

\begin{abstract}
The contribution presents the faculty development program of the University of Milano-Bicocca, called "Teaching large classes". The objective of this paper is to illustrate the training structure of this project (launched in 2016 with a series of pilot actions that became fully operational the following year) and its recent developments. The paper intends to provide a detailed description of the three main principle that shape the structure of the training program: the continuum of immersion and distancing in training methodologies; the isomorphism between learning contents and teaching methodologies; the focus on the didactic transposition and education reconstruction process. The analysis of these principles shows that the interand trans-disciplinary approach of the training program is a crucial condition to the interconnectedness of the three principles in a consistent training structure. Furthermore, the multi- inter- and transdisciplinary approach allows for the development of the project with a broader scope.
\end{abstract}

Keywords: Teaching large classroom; faculty development; didactic transposition; interdisciplinary approach; teacher training. 


\section{Introduction}

This contribution is intended to present the faculty development project of the University of Milan-Bicocca, with particular focus on the workshop "Teaching large classes" which is designed for the faculty members of the University of Milan-Bicocca and coordinated by a group of researchers from the Department of Human Sciences for Education "Riccardo Massa” (Nigris, Balconi, Passalacqua, 2019; Nigris, 2018).

The aim of this contribution is to illustrate the training structure of this project, which was launched during the 2016/2017 academic year with a series of pilot actions that became fully operational the following year, and, at the same time, to present the developments that arose during the last annuity of the project. With regard to the structure of the paper, we intend to focus on three main principle that shape the structure of the training program: the continuum of immersion and distancing in training methodologies; the isomorphism between learning contents and teaching methodologies; the focus on the didactic transposition and education reconstruction processes.

\section{Genesis and structure of the training proposal of the University of Milan- Bicocca}

The faculty development project promoted by the University of Milan-Bicocca started with the realization of professional development's complexity and its debt to the disciplinary domain of scholars and faculty members. Both the habit of teaching specific disciplinary areas and also the epistemology at the basis of the research activity of the individual teachers play a crucial role in guiding and influcining the transformation conditions of teaching practices (Nigris, Balconi, Passalacqua, 2019); based on the consideration of this disciplinary specificity, the University of Milan-Bicocca has entrusted the development of the project to a team of teachers, coordinated by Prof. Nigris and to a group of researchers coming from different disciplinary fields and departments. This team was established during the 2016/2017 academic year with the involvement of scholars who shared a decade of experience in teacher training, specifically at the primary and secondary levels. The purpose of creating such team was to set up a working group capable of continuously supporting the training needs of scholars belonging to 14 different departments and to facilitate the dialogue between colleagues pertaining to didactic issues, taking as a reference the model of communities of academic practice (Barret et al., 2009)

Consistent with this general framework, the training proposal of the program was structured on three levels - listed below - to offer a gradation in faculty members' professional development process. 
1. First level workshop "Teaching large classes", full immersion, 12 hours. Since the workshop started in June 2017 (first pilot edition) more than 200 professors have participated. Starting from January 2018 and thanks to a participatory evaluation process of the pilot edition, this workshop has also been addressed to newly-entered researchers.

2. Second level workshop "Student learning and formative assessment" aimed only at professors who participated in the first level workshop, full immersion, 8 hours. During the various editions, more than 50 teachers participated. The workshop starts with a small group analysis of the participating professors' teaching documentation, in particular exams given to students, and then focuses on specific aspects related to formative assessment and monitoring of learning.

3. Individual consultations to teachers who request it and who participated in the first level workshop. These consultations mainly concern aspects related to the design of individual courses and the monitoring of students' learning. Over the three years of the project, more than 30 consultations have been offered to scholars from 7 different departments.

\section{The three principles of the training program}

The faculty development program of the University of Milan-Bicocca revolves around three design elements, briefly presented below. These elements have been progressively explored during the various years of the project by investigating the training impact

\subsection{From the teacher's to the student's perspective (part I): the immersion/distancing continuum of teaching methodologies}

The teaching methodologies that structure the two main training proposals of the course (workshop of first and second level) are designed to be arranged along the immersiondistancing continuum (Rossi, 2011). In fact, there are immersive-simulation methodologies (watching videos of didactic activities; simulations of didactic situations; role-play) which have the function of facilitating an immediate recognition of the topics covered by the training and of mobilizing the implicit didactic knowledge of the participating teachers. The distancing methodologies (such as debriefing or large group discussions), on the other hand, play a role of progressive re-reading of teaching practices through the interpretative schemes offered by the course. This immersion/distancing recursion also responds to the objective of offering participants the opportunity to take the students' point of view. This process, which aims to facilitate the transition of teachers from a teacher-centred to a student-centred approach to teaching, is dependent on a second principle, defined as isomorphism between learning content and teaching methodologies. The debriefing activities, in particular, serve to make participants analyse the training course on a double 
level: a) the learning contents and teaching methods used in the training course; b) the choices and actions of the teacher-trainer made during the workshop.

\subsection{From the teacher's to the student's perspective (part II): isomorphism principle between learning contents and teaching methodologies}

The thematization of this double level for which "the teaching-learning process constitutes at the same time the object of the lessons, but also the medium through which future teachers experience the relational, communicative and teaching methods that they will propose to their future students" (Nigris, 2006), is implemented during the workshop through a continuous and explicit meta-cognitive reference to this interweaving of levels. The purpose of this reference is to encourage participants with a dual perspective: as students, immersed - from within - in the learning process and focused on the content to be learned; as teachers, asked to consider the choices of the teacher-trainer and led to observe the evolution and effects of the training process from the outside. This double level refers to the principle of isomorphism (Baldacci, 2006; Porlan, 2017) between the content taught and the didactic methods adopted, and it allows us to understand the choice of entrusting the faculty development training actions to teachers who have substantial experience in teacher training.

\subsection{From the teacher's to the scholar's perspective: the role of transposition and education reconstruction in facilitating the student's conceptual change}

A further objective of the training proposals is the reflection on the selection of disciplinary contents and on the methods of learning by non-experts in a specific disciplinary area (as are the students and, during the training course, the teachers who participate). For this reason, training activities are intended to focus on some variables of the didactic transposition (Chevallard, 1985) and the educational reconstruction process (Duit et al., 2012), mostly related to the knowledge of the discipline and the exploitation of the students' pre-knowledge. Studies on the conceptual change in the teaching-learning process (Pozo, 1999; Vosniadou, 2009) recognize the active role of the students' pre-knowledge in the construction processes of new concepts and, therefore, the need to make that preknowledge visible (Ritchhart, Perkins, 2008) in order to be able to progressively modify it. Furthermore, such knowledge is fixed to an "articulated cognitive structure", using the definition offered by Quinn and Holland (1987), in folk theories or in "implicit theories" (Pozo, 1999) since they possess interpretative functions that allow us to analyze the phenomena of reality, elaborate hypotheses and make inferences (Pozo, Del Puy, Sanz, Limon, 1992). To develop competences of accompanying the conceptual construction, teachers, as a prerequisite, are required to know how to recognize such prior knowledge in order to understand and structure a concept. A preliminary step for the development of this competence is to deepen the communication aspects that govern the interaction in the 
classroom between teachers and students, especially in the context of large classes. In this learning environment, it is essential that the teacher is able not so much to ask students general questions, but rather to formulate specific questions that can activate complex reasoning (Selleri, 2016) and conduct collective reasoning and discussions (Pontecorvo, 1993) that can enhance the heterogeneity and the numerousness of the group of students.

\subsection{Multidisciplinarity, interdisciplinarity and transdisciplinarity as conditions for the training of university teachers}

The principle that guides the implementation of the faculty development program responds to the idea that the multi-, inter- and transdisciplinary training approach can facilitate the development of didactic skills for university teaching. In particular, it is believed that the dialogue between different disciplinary areas and epistemologies is able to favour the development of these skills by guiding the didactic transposition and educational reconstruction of the teacher. In this sense, higher education teaching skills are not only dependent on the communication skills of the professors and on their ability to engage students, but above all they concern the ability to accompany students' conceptual construction and, before that, the ability to identify the conceptual issues of greater relevance to a specific disciplinary area and to relate these issues to the knowledge already held by students. To encourage the development of these skills, the team of researchers who initiated the faculty development program established a training structure based on different levels of disciplinary interaction:

1. Multidisciplinary level: a) The team of researchers from different disciplinary areas coordinates the University's educational program. These scholars have the role of privileged interlocutors in the analysis of training needs of the different departments; b) Groups of teachers participate in the training interventions (the main criterion for the formation of the groups relates to the disciplinary origin of the participating teachers).

2. Interdisciplinary level: The activities that structure the three modules of the workshop "Teaching large classes" are defined and require participants to enter into a dialogue with colleagues from different disciplinary fields.

3. Transdisciplinary level: The objectives of the training interventions concern the development of didactic professional skills of the participants. In this sense, reference is made to a disciplinary area that does not belong to a processing previously implemented by the participating teachers.

As illustrated in a previous work, (Nigris, Balconi, Passalacqua, 2019), the data collected at the end of each different edition of the workshop, regarding the training impact perceived by the participants, shows that the activity of the third module (see Table 1) was appreciated by the teachers for having favoured a reflection on the didactic choices in the 
selection of the conceptual keys of their discipline. In particular, data taken from pilot training assessments show that participants greatly appreciated the multidisciplinary composition of the training group, the dialogues with colleagues from other departments on specific content of teaching and the consideration of students as "non expert scholars".

For example, see some excerpts from the participants' comments which highlight the role of the comparison between different disciplinary perspectives in allowing unprecedented ways of reading the teaching variables.

Working with people from other disciplines is very interesting in my opinion, it gives you a lot of ideas. And not only because you don't have that competence, but also because it shows you another way of seeing things (...). Yes, she managed to put the content in the right wrapping.

The feedback of the participants underlines how the interdisciplinary comparison helps us to elaborate an epistemological reflection that facilitates the recognition of the didactic specificity of the different disciplinary teaching areas.

This work of debate between colleagues from different disciplines served to focus on conceptual passages that I took for granted; it helped me to understand what a priority is in our disciplines. (...) For example, check what the real problem that you want to consider is.

It can be said that the participants in the workshop "Teaching large classes", through the activity of explaining to a colleague a difficult concept of their discipline, began to question their own didactic planning and the choices related to the selection of learning contents. From this point of view, it can be seen as a first step from a teacher-centred approach to a student-centred approach in the choice of learning contents.

As the problem seemed to be the students' prior-knowledge, my colleague helped me to think about how this knowledge was managed during the course. For example, to find some background questions a few days before discussing the concept ... in order to start from there. I have a lot of experience in teaching physics, I must say that now I understand well what it means to teach physics to opticians and physics to physicists. It changes a lot, especially compared to what students know before starting the course and how they think about the experiments I often do.

\section{An outcome of the three-year program: the definitive structure of the first level workshop}

Now take a closer look at the training structure of the first level workshop "Teaching large classes" that is the result of the research conducted on the workshop over the course of three years of the faculty development program. This training intervention, which includes three consecutive 4-hour modules (arranged over two days), is designed around three main activities. Each activity is initiated as a module with the aims to promote both immersive 
and experiential learning methods and processes of reflective distancing (debriefing activities).

Table 1: Structure of workshop modules "Teaching large classes"

\begin{tabular}{|c|c|}
\hline Module & Activity \\
\hline $\begin{array}{l}\text { First module } \\
(4 \mathrm{hrs})\end{array}$ & $\begin{array}{l}\text { Video analysis of a lesson in a large classroom context: individual and pair } \\
\text { activity of analysis of two lessons conducted in different disciplinary areas. } \\
\text { Debriefing conducted by the teacher trainer. }\end{array}$ \\
\hline $\begin{array}{l}\text { Second } \\
\text { module } \\
(4 \mathrm{hrs})\end{array}$ & $\begin{array}{l}\text { Analysis of didactic communication in a large classroom context: simulation of } \\
\text { an interaction activity between teacher and student (conducted by the teacher } \\
\text { trainer) focused on the use of questions to elicit the students' previous } \\
\text { knowledge and mis-conceptions. Debriefing conducted by the teacher trainer. }\end{array}$ \\
\hline $\begin{array}{l}\text { Third module } \\
(4 \mathrm{hrs})\end{array}$ & $\begin{array}{l}\text { Simulation of a didactic activity in pairs: the members of the couples, selected } \\
\text { on the basis of a criterion of disciplinary diversity, are asked to explain to their } \\
\text { colleague a topic of their respective research and teaching areas considered } \\
\text { difficult for students. Debriefing conducted by the teacher trainer. }\end{array}$ \\
\hline
\end{tabular}

The objectives that we intend to pursued in the "Teaching large classes" workshop can be summarized in the following four points: a) promoting a greater awareness in faculty members of their own teaching style and of the teaching models proposed in the classroom; b) sensitize professors to the different profiles of students and to the need to decline educational paths and mediators according to the recipients of the teaching-learning process and to their level of disciplinary knowledge; c) guide professors in the transition from teaching content to identifying and constructing complex concepts relating to different disciplinary areas; d) focus the attention of professors on the relationship between the epistemology of the discipline and the teaching methodologies. While the first outcome is related to a general objective of the program, the latter three outcomes refer to a development area that could be called "disciplinary awareness on the teaching and learning process". Within this area, the three modules of the workshop are directed to guide faculty members to reflect on the interconnection between their disciplinary research and teaching activity and, more precisely, to support them in thinking about teaching not as an isolated professional requirement, but rather as a direct result of conducting research.

\section{Expansion of the training project}

At the end of the first three years of the project, the interdisciplinary team that has been coordinating the faculty development proposals of the University has developed some new 
actions, to be implemented during the current year, that aim to extend the effectiveness of the ongoing program:

- In-depth groups: The questionnaires given at the end of the first and second level workshops highlight the participants' requests for in-depth meetings on some specific issues (in particular with respect to group work in the context of large classes and the design of the teaching structure). This action has been implemented as a part of the community of practice framework (Barret et al., 2009).

- Tutor training: Thanks to the work of the multidisciplinary theme, a specific training project to facilitate the quality of learning for the students of the three-year degree courses in science and economics has been launched for academic staff with tutoring roles. This action is aimed at developing professional figures who are able to identify the specific training needs of students with reference to the contents of disciplinary learning and to prepare teaching strategies to support the modality of large classes.

- Further adjustment of the first level workshop structure: In order to encourage continuous support in improving the teaching practices of the participants, a fourth module has been introduced to the workshop "Teaching large classes". This module, to be carried out two months after from the first three, intends to foster a comparison of the didactic innovation experiences developed by the participants and aims to support the professional training project with a more focused analysis on individual teaching practices.

\section{References}

Baldacci, M. (2006). Ripensare il curriculum. Principi educativi e strategie didattiche. Roma: Carocci.

Barrett, M. S., Ballantyne, J., Harrison, S., \& Temmerman, N. (2009). On building a community of practice: reflective narratives of academic learning and growth. Reflective Practice, 10(4), 403-416.

Chevallard, Y. (1985). La transposition didactique. Du savoir enseignant au savoir enseigné. Grenoble: La Pensée Sauvage.

Duit, R., Gropengießer, H., Kattmann, U., Komorek, M., And Parchmann, I. (2012). The model of educational reconstruction. A framework for improving teaching and learning science. In: Jorde D. And Dillon, J. (eds.) Science education research and practice in Europe. Rotterdam: Sense Publishers, pp. 13-37.

Nigris, E. (2018). Learning to teach: the pilot programme to improve faculty members teaching skills at the University of Milano-Bicocca. Form@re-Open Journal per la formazione in rete, 18(1), pp. 53-66.

Nigris, E., Balconi, B., \& Passalacqua, F. (2018). Accompagnare il processo di concettualizzazione disciplinare degli studenti universitari: un percorso co-disciplinare e trans-disciplinare per la formazione didattica dei docenti universitari. Il caso dell’Università di Milano Bicocca. Education sciences \& society, 9(2), pp. 270-286. 
Pontecorvo, C. (1993). Forms of discourse and shared thinking. Cognition and Instruction, 11(3-4), pp. 189-196.

Porlan, R. (2017). Enseñanza universitaria. Cómo mejorarla. Madrid: Morata.

Pozo, J. I. (1999). Más allá del cambio conceptual: el aprendizaje de la ciencia como cambio representacional. Enseñanza de las ciencias: revista de investigación y experiencias didácticas, 17(3), pp. 513-520.

Pozo, J. I., del Puy Pérez, M., Sanz, A., \& Limón, M. (1992). Las ideas de los alumnos sobre la ciencia como teorías implícitas. Infancia y aprendizaje, 15(57), pp. 3-21.

Ritchhart, R., Church, M., Morrison K. (2011). Making thinking visible: How to promote engagement, understanding, and independence for all learners. San Francisco: JosseyBass.

Ritchhart, R., Perkins, D. (2008). Making thinking visible, Educational leadership, LXV, 5, 57-61.

Rossi, P. G. (2011). Didattica enattiva. Complessità, teorie dell'azione, professionalità docente. Milano: FrancoAngeli.

Selleri, P. (2016). La comunicazione in classe. Roma: Carocci. Van Dijk, E. M., Kattmann, U. (2007). A research model for the study of science teachers' PCK and improving teacher education. Teaching and Teacher Education, 23(6), 885-897.

Vosniadou, S. (2009). International handbook of research on conceptual change. New York, NY: Routledge. 